The Association of Group-based Discrimination with Health and Well-being:

\author{
A Comparison of Ableism with Other “isms” \\ Carla Branco $^{1}$, Miguel R. Ramos ${ }^{1,2}$, \& Miles Hewstone ${ }^{2}$ \\ ${ }^{1}$ Instituto Universitário de Lisboa (ISCTE-IUL); CIS-IUL \\ ${ }^{2}$ University of Oxford
}

\begin{abstract}
Author's note:
Address correspondence to Carla Branco, Instituto Universitário de Lisboa (ISCTE-IUL), CIS-

IUL, Lisbon 1649-026, Portugal. Email: (carla_branco@iscte-iul.pt). This research was supported by a grant from the Portuguese Foundation for Science and Technology (FCT, PD/BD/128323/2017) awarded to the first author.
\end{abstract}




\begin{abstract}
Discrimination has negative consequences for the health and well-being (HWB) of individuals belonging to disadvantaged groups. Due to social and attitudinal barriers, we argue that disabled people comprise one of the groups most affected by discrimination. Using data from the European Social Survey, including representative samples from 32 countries surveyed in seven waves (2002-2014), we compared the effects of ableism on HWB with discrimination targeting other groups (e.g., sexism, ageism). We tested these effects between individuals (i.e., comparing the effects of individuals belonging to different disadvantaged groups) and within individuals (i.e., examining the case of individuals belonging to multiple disadvantaged categories). Results indicated that facing ableism is associated with lower HWB, and that this effect has a greater magnitude when compared to the effect of being discriminated because of other disadvantaged group memberships. Our findings highlight the significance of addressing ableism in research and social policy.
\end{abstract}

Keywords: Discrimination; disability; ableism; health and well-being. 
The Association of Group-based Discrimination with Health and Well-being:

A Comparison of Ableism with Other “isms”

Group-based discrimination has deleterious consequences for the health and well-being of individuals belonging to disadvantaged groups (Pascoe \& Smart-Richman, 2009; Schmitt, Postmes, Branscombe, \& Garcia, 2014). These are well-known and established effects, but a curious paradox remains in this field of research - although disabled people are one of the largest social minorities (15\% of the world's population; World Health Organization [WHO], 2011), they have received much less societal and academic attention than other disadvantaged groups (e.g., racial minorities). This is, for example, evident with the use of Google searches, which have been validated as measures of social attitudes (Stephens-Davidowitz, 2014) and we use them here to illustrate the relative salience of societal attitudes towards disadvantaged groups. Examining the relative 'popularity' of Google searches worldwide in the last ten years, we found that "racism" averaged a popularity of 43.5, compared with "sexism" (18.1), "ageism" (1.6), and "ableism" (1.04) ${ }^{1}$. Using other more common terms such as “disability discrimination” instead of ableism, or "age discrimination” instead of ageism, revealed the same order of popularity. This paradox is likely to reflect extant norms and societal priorities, whilst mirroring this group’s status in multiple societies. In this paper, we compare the effect of group-based discrimination against different groups (e.g., ableism, ageism, sexism) on health and well-being. We argue that disabled people may comprise one of the disadvantaged groups that suffers the most from discrimination and, in the face of such evidence, it would be appropriate to challenge this relative lack of knowledge of their plight.

\footnotetext{
${ }^{1}$ We used Google Trends, which compares terms searched during a specified period of time and provides a “popularity score" for each term, ranging from 0 to 100. One-hundred represents peak popularity, 50 represents medium popularity, and 0 means there were no data available for that term. This analysis was performed on the $13^{\text {th }}$ of March 2019.
} 


\section{Conceptualizing Disability}

According to the social model of disability (Oliver, 1983; Oliver \& Barnes, 2010;

Shakespeare, 1996), disability derives directly from environmental, social, and attitudinal barriers, contrasting with the individual and medical model (Brisenden, 1986), which focuses the problem on individuals’ bodies and minds. Defining disability as a societal problem derived from social barriers, rather than an individual issue, places the onus of change on society (Olkin \& Pledger, 2003). Throughout this research, in line with the social model of disability and in accordance with the Movement and Organizations of Disabled People, we use the term “disabled people” to mean that "people are disabled by environmental, systematic, and attitudinal barriers in society, rather than by their impairment” (European Network on Independent Living, 2018). In fact, this term has been commonly used by disability rights activists and in disability studies, since the early 90s, as a marker of identity of a group bounded by common social and political experiences (Linton, 2006). It allows disabled people to claim disability as an important aspect of their identity (Dunn \& Andrews, 2015), while the onus of social construction and change remains on society.

Disability has become a broader category over time, incorporating people with a wide range of conditions. According to the Convention on the Rights of Persons with Disabilities [CRPD] (United Nations [UN], 2006, art. 1, p. 4), disabled people are "those who have longterm physical, mental, intellectual or sensory impairments which in interaction with various barriers may hinder their full and effective participation in society on an equal basis with others”. Therefore, mental, neurological, or chronic health conditions causing long-term impairments, which in interaction with various barriers may hamper full participation in society, could be considered disabilities. In addition, Bogart and Dunn (in press) note that, from a social model 
perspective, anyone self-identified or identified by others as having a disability can be considered as such. This broad and inclusive definition of disability is adopted throughout our research.

\section{Ableism: Discrimination toward Disabled People}

Stigma is generally based on an attribute and serves as a motive to discount a person and to believe that they are not quite human, supporting discrimination and reducing the target's life opportunities (Goffman, 2006). Ableism has been mostly addressed in disability studies and conceptualized as a set of beliefs and practices that marginalize disabled people and subject them to a “diminished state of being human” (Campbell, 2001, p. 44), through the postulation of an abled corporeal standard that is essential and fully human. It is based on the belief that impairment is inherently negative and the cause of the problems experienced by disabled people (Campbell, 2008), masking the role of the social environment. As such, we argue that ableism is in line with the individual and medical perspective on disability. Moreover, the endorsement of such a perspective is related to the legitimization of the status quo (Dirth \& Branscombe, 2017) and justifies the social segregation of disabled people. In this study, we adopt the broad definition, proposed by Bogart and Dunn (in press), equivalent to social psychological definitions of other "isms”: “Ableism is stereotyping, prejudice, discrimination, and social oppression toward people with disabilities” [note to editors: add page number once Bogart and Dunn is published].

Research shows that able-bodied individuals tend to have negative attitudes towards disabled people, as well as negative emotional reactions, such as anxiety, avoidance and ambivalence (Dovidio, Pagotto, \& Hebl, 2011; Vilchinsky, Findler, \& Werner, 2010). A metaanalysis showed a consistent pattern of moderate to strong negative implicit attitudes toward 
disabled people (Wilson \& Scior, 2014). Over the years, research has identified multiple sources of negative attitudes toward disabled people. These include, for example, social and cultural conditioning, moral beliefs about disability (perception of disability as a punishment for a committed sin or as a justification for a future evil act, triggering unconscious fear), fear of death due to the parallelism between disability and death, and negative stereotypical reactions typically associated with marginalized group members (Dunn, 2015; Livneh, 1982, 1988).

According to the stereotype content model (Cuddy, Fiske \& Glick, 2008; Fiske, Cuddy, Glick, \& Xu, 2002; Fiske, Xu, Cuddy, \& Glick, 1999), there are two fundamental dimensions of social perception - warmth and competence - that, in combination, generate distinct emotions of admiration, contempt, envy, and pity. Disabled people have been associated with low competence and high warmth, a combination that elicits pity and sympathy emotions, and thus paternalistic prejudice (Cuddy et al., 2008; Fiske et al., 1999; Fiske et al., 2002). At an implicit level, however, disabled people are associated with both low competence and low warmth (Rohmer \& Louvet, 2012) - the least positive of the four quadrants that result from crossing low/high warmth with low/high competence. This profile is associated with dehumanization (Harris \& Fiske, 2006) and is often only attributed to marginalized groups such as drug addicts and homeless people ${ }^{2}$. Recent studies have shown that implicit prejudice toward disability increased over time between 2004-2017 (Harder, Keller, \& Chopik, in press). In addition, disabled people's experiences of ableism are associated with paternalism (e.g., unwanted help, infantilization), dehumanization, objectification, hostility (Nario-Redmond, Kemerling, \&

\footnotetext{
${ }^{2}$ This discrepancy, between explicit and implicit levels, could be explained by the fact that implicit measures offer less opportunity to control responses, blocking the explicit stereotype content associated with the normative protected group (Rohmer \& Louvet, 2012).
} 
Silverman, in press), and with denial of equal rights and invalidation (Olkin, Hayward, Schaff, \& VanHeel, in press).

Our argument is that ableism targets a particularly vulnerable group and, as such, may have critical and deleterious consequences for disabled people’s health and well-being. One of the reasons for this vulnerability stems from the poor socioeconomic conditions and multiple forms of social exclusion to which they are exposed. Due to social and attitudinal barriers, disabled people tend to have poorer access to health services, education, and employment, together with a higher risk of exposure to violence and poverty (UN, 2015; WHO, 2011). Compared to the nondisabled, disabled people have a higher prevalence of secondary chronic diseases and are less likely to receive preventive care (Reichard, Stolzle, \& Fox, 2011).

Moreover, evidence shows that disability seems to play a central role when compared to other social categories. For instance, the magnitude of socioeconomic disadvantage is lower between disabled women and men, compared to the magnitude between nondisabled women and men (Kavanagh et al., 2015). Perceived gender differences are minimized between disabled women and men, when compared to perceived gender differences between nondisabled men and women (Nario-Redmond, 2010). In line with these findings, research has also shown that blind targets were rated as ruder and less warm after confronting patronizing help, regardless of their gender (Wang, Walker, Pietri, Ashburn-Nardo, in press). In addition, Rohmer and Louvet (2009) found that disabled people are immediately described by disability, independent of their sex or ethnicity, suggesting that disability could be a primary, superordinate and highly salient category. This is supported by a meta-analysis reviewing the effects of perceived discrimination on psychological well-being (Schmitt et al., 2014). Although this work did not compare directly between different types of discrimination, the meta-analysis revealed weaker effect sizes for 
racism and sexism and larger effect sizes for ableism. Taken together, this body of work suggests that, due to the vulnerable position of disabled people, ableism could be one of the most damaging forms of group-based discrimination.

\section{The Present Study}

We compare the effects of ableism with the effects of facing discrimination as a member of other disadvantaged groups on health and well-being. We hypothesized that, compared to discrimination against other stigmatized groups (e.g., sexism), discrimination against disabled people would have a stronger (negative) effect on health and well-being. To test this hypothesis, we examined these effects between individuals (i.e., comparing the effects of individuals enduring different types of group discrimination; Analysis 1) and within individuals (i.e., examining the case of disabled individuals belonging to multiple disadvantaged categories; Analysis 2). While Analysis 1 allows for a comparison between individuals who belong to various stigmatized groups and thus accounts for a broad range of demographic backgrounds, Analysis 2 focuses only on disabled individuals who also belong to at least another stigmatized category. The latter analysis provides a comparison between disabled people and tests, within this group, whether being discriminated on the grounds of disability has a stronger effect on health and well-being than other types of discrimination. In Analysis 2, because all individuals are disabled, it serves to mitigate the effects of unmeasured variables associated with the different stigmatized groups.

\section{Analysis 1 - Effects of Group-based Discrimination between Individuals}

To address our research question, we analyzed data from the European Social Survey (ESS). This large cross-country survey included nationally representative samples, generated through random probability sampling, from 36 European countries and, at the time of our study, 
seven waves of cross-sectional data. The ESS is an academically driven and repeated crossnational survey conducted across Europe from 2001 until the present year. Data were collected through face-to-face interviews and included a wide range of measures assessing attitudes, beliefs, and behavior patterns. The ESS has been used across various disciplines (e.g., sociology, social policy, psychology), resulting in multiple publications relevant for social policy and practice.

\section{Respondents}

We selected for analysis all individuals who responded affirmatively to the question "Would you describe yourself as being a member of a group that is discriminated against in this country?”, resulting in a total sample available for analysis of 18,660 respondents, from 32 countries. Of these respondents, 53\% were female, 34\% were disabled, $26 \%$ were from an ethnic minority background, and 13\% were older adults (i.e., individuals who were 65 and above). On average, respondents of this sample were 42.8 years old $(S D=16.5)$ and had 12.7 years $(S D=$ 4.2) of full-time education completed. More details about our sample are reported in see Table 1.

\section{Measures}

Group-based discrimination. The perception of discrimination based on group background was measured with the question, “On what grounds is your group discriminated against?" in which respondents could choose either "no" (0) or "yes" (1) across several options from the following list: “Color or race”, “Nationality”, “Religion”, “Language”, “Ethnic group”, “Age”, “Gender”, “Sexuality”, and “Disability”. For our analysis, all of these options were used as separate dummy variables and introduced in our model as independent variables to assess perceptions of group-based discrimination. Table 2 shows the number of respondents that responded “yes” to each option and percentages by country. 
Health and well-being (HWB). The WHO (2005, p. 1) defines health as "a state of complete physical, mental and social well-being and not merely the absence of disease or infirmity”. Thus, health (and well-being) cannot be reduced to a single factor. As such, we measured health and well-being by averaging answers to questions on self-rated happiness, satisfaction with life, and health: “Taking all things together, how happy would you say you are?” (answers ranging from 1, “extremely unhappy” to 10, “extremely happy”); “All things considered, how satisfied are you with your life as a whole nowadays?” (answers ranging from 0, “extremely dissatisfied” to 10. “extremely satisfied”); and "How is your health in general?” (answers ranging from 1, “very good” to 5, "very bad”), which was reversed-scored. Responses to the three questions were standardized and then averaged to yield a measure of HWB ( $\alpha=0.71$, with only one factor explaining 65\% of the variance emerging from an exploratory factor analysis). A higher score on this variable indicated better HWB. Table 3 shows HWB mean scores by group-based discrimination and country. In support of our measure, self-reported measures of general health, happiness, and satisfaction with life have been widely used to measure health and well-being (e.g., Pascoe \& Smart-Richman, 2009; Schmitt et al., 2014), and these three measures have been found to be highly correlated in previous research (Clark \& Oswald, 1994; Kahneman \& Sugden, 2005).

Individual-level controls. We controlled for a wide range of relevant individual-level characteristics, associated with health and well-being (e.g., Wilkinson \& Marmot, 2003). We included the following variables and coding: sex $(1=$ Male $)$, born in country $(1=$ No); belonging to minority ethnic group in country (1= Yes); hampered in daily activities by illness/disability/infirmity/mental problem ( 1 = Yes); belonging to a religion $(1=$ No); marital status coded with 4 dummies, using the reference group "Married” (1 = Separated; 2 = Divorced; 
3 = Widowed; 4 = Never married); employment status, coded with 2 dummy variables, with the reference group “Employee” (1 = Self-employed, and 2 = Working for own family business); ever unemployed and seeking work for a period more than three months ( 1 = Yes); and, feeling about household's income, coded with 3 dummy variables, using the reference group "Coping on present income” (1 = Living comfortably on present income; 2 = Difficult on present income; 3 $=$ Very difficult on present income). We also controlled for other continuous and ordinal variables for which we maintained the original coding. These included age; years of education completed; how often meet socially with friends, relatives or colleagues; take part in social activities compared to others of same age; state of education in country; and state of health services in country.

Country-level controls. To account for contextual variables associated with individual health and well-being (e.g., Marmot, Allen, Bell, Bloomer, \& Goldblatt, 2012), we included additional variables at the country-level. These variables included macro-level indicators such as country wealth, social inequalities, and life expectancy. Country wealth was measured with the gross domestic product (GDP per capita in current US\$) using World Bank data. We created a social inequalities measure using a dissimilarity index (Massey \& Denton, 1988) containing respondents' educational distributions. Life expectancy was measured with life expectancy at birth (in years) using World Bank data. These data were matched by country and year. A higher score on these variables indicates, respectively, higher wealth, social equality, and life expectancy.

\section{Procedure}

The ESS is not longitudinal and in each wave different respondents were sampled. With this characteristic in mind, we performed a multilevel repeated cross-sectional analysis 
(Fairbrother, 2014) within the structural equation modeling (SEM) framework, using Mplus 8.0. This approach allowed us to account for dependence due to the hierarchical structure of the data (i.e., individuals nested within countries and waves), through a three-level model in which respondents were nested within country-waves, which in turn were nested within countries. With this model specification, it is possible, at a higher hierarchical level, to control for differences between countries by introducing a coefficient representing the mean of each country-level variable across all available waves for each country. It also allowed us, at an intermediate level, to control for within country changes by introducing a coefficient representing how much a country had changed in each wave relative to its mean value across waves. Therefore, we had two coefficients per variable by disaggregating each variable into a between-country coefficient (time-invariant) and a within-country coefficient (time-variant, representing change). We also included in our equation a linear effect of time, through the inclusion of a variable corresponding to survey year, to account for time trends in coefficients. This method provided the added value of accounting for differences between countries, whilst accounting for within-country changes. Moreover, this modeling technique allowed us to take full advantage of all waves of the ESS and to consider the evolving nature of the social context in which respondents were embedded.

At the individual-level, we coded all “don’t know”, "refuse to answer”, and no responses as missing values. The total number of missing values in the ESS is generally low (around 5\%). We used full information maximum-likelihood estimates with robust standard errors (MLR), which allows estimation with missing data and produces less biased results than other methods (Little \& Rubin, 2000). This estimation method has the advantage of using all observed data. In addition, we used a variable to weight the sample, composed by an interaction of design weight and population size weight. Design weight allows us to correct for possible sample 
selection bias, related to the inclusion probabilities of some individuals in the population.

Population size weight guarantees that each country is represented in proportion to its population size. These weights are provided by the ESS to adjust for sampling error, allowing us to obtain more accurate estimates based on the proportion of individuals in society.

In this analysis, we compared the effects of group-based discrimination on the HWB of people belonging to different disadvantaged groups, by simultaneously introducing all types of group-based discrimination in our analysis. We first estimated a model without control variables, followed by a model controlling for both individual- and country-level variables. We then used a z test to compare dependent and overlapping correlations (Dunn \& Clark, 1969) between groupbased discrimination against the different groups. To avoid having multiple comparisons of all groups, we compared only those who showed a statistically negative effect of group-based discrimination on HWB.

\section{Results}

The SEM multilevel model yielded a good fit as shown by the comparative fit index (CFI), root mean square error of approximation (RMSEA), and standardized root mean square residual $(\mathrm{SRMR})$ indices $(\mathrm{CFI}=0.99 ; \mathrm{RMSEA}=0.001 ; \mathrm{SRMR}=0.001)$. Comparison between models revealed that the model including the control variables had higher predictive power than the model without the controls, as shown by the lower scores in the fit indicators (i.e., log-likelihood, Akaike information criterion, and Bayesian information criterion) and by a lower proportion of unexplained variance (Table 4$)^{3}$. Results showed that only discrimination based on age, $b=$ $.133 ; p<.001$, and disability, $b=-.267 ; p<.001$, were negatively and significantly associated with lower HWB. When compared to the effect of being discriminated based on age, the effect of

\footnotetext{
${ }^{3}$ Main effects were the same in both models (except for gender which was significant without control variables), indicating that control variables did not cancel out or reverse the main effects.
} 
discrimination based on disability had a greater magnitude, $z=-13.4726, p<.001$. This finding suggests that discrimination based on disability (i.e., ableism) has a stronger negative effect on HWB, compared to the effects of discrimination based on membership of other disadvantaged groups, supporting our hypothesis. Discrimination scores based on race, $b=-.063 ; p=.079$, nationality, $b=-.040 ; p=0.226$, language, $b=-.022 ; p=0.706$, ethnicity, $b=-.024 ; p=.532$, and gender, $b=.007, p=.800$, did not have statistically significant impacts on HWB. In contrast, some disadvantaged groups showed a positive association with HWB. This was the case for discrimination based on religion, $b=.195 ; p<.001$, and sexuality, $b=.126 ; p=.010$. One reason that could explain weaker effects of discrimination would be the perceived illegitimacy of discrimination based on some of these groups (Schmitt et al., 2014), which is associated with a higher minority group identification (Jetten, Schmitt, Branscombe, Garza, \& Mewse, 2011). Positive effects of discrimination have been reported in previous research where there is a strong minority group identification. Research has shown that ingroup identification emerges in the face of discrimination, acting as a buffer of the negative effects of discrimination on well-being (Branscombe, Schmitt, \& Harvey, 1999; Ramos, Cassidy, Reicher, \& Haslam, 2012).

\section{Analysis 2 - Effects of Group-based Discrimination within Individuals}

In this analysis we also used ESS data but with a different approach as we considered for analysis only disabled individuals.

\section{Respondents}

We used a combination of disability together with other social categories (i.e., sex, age and ethnicity), which appeared in combination with disability, resulting in five subsamples in which disability was always present: disabled women $(n=39,091)$, disabled person over 65 years old $(n$ $=25,659)$, disabled person with a minority ethnic group background $(n=3,699)$, disabled 
women over 65 years old $(n=15,199)$, and disabled women with a minority ethnic group background $(n=2,065)$. These are the most common associations of multiple categories including disability in the literature. Note that we also considered the possibility of including individuals who belonged to more than three disadvantaged groups, but this resulted in small sample sizes, producing unreliable estimates. Moreover, as a more conservative test of our hypothesis, we excluded categories that showed a positive association with HWB in Analysis 1 (religion and sexuality) or were not available in the survey to select as a subsample.

\section{Procedure and Measures}

We used the same measures and procedure as in the previous analysis. However, we now selected the subsample of individuals who were disabled by including all those who had responded "Yes a lot" and "Yes to some extent" to the question, "Are you hampered in your daily activities in any way by any longstanding illness, or disability, infirmity or mental health problem?” In this analysis, we compared the effects of group-based discrimination within the five subsamples of multiple social categories described above. As in our previous analysis, we used a $z$ test (Dunn \& Clark, 1969) to compare the statistically negative effects of group-based discrimination on HWB.

\section{Results}

The SEM multilevel models yielded a good fit to the data $(\mathrm{CFI}=0.99$; $\mathrm{RMSEA}=0.001$; SRMR $=0.001)$. Results supported our initial findings, such that discrimination based on disability had a stronger negative impact on HWB, when compared to the effect of multiple disadvantaged social categories (see Table 5). We report below all group combinations and compare the effects of being discriminated on the grounds of disability with the effects of being discriminated because of another category. 
Gender and disability. The effect of discrimination based on disability, $b=-0.522 ; p<$ .001 , had a greater magnitude, $z=63.709, p<.001$, on the HWB of disabled women compared to the effect of being discriminated based on gender, $b=-.130 ; p=.037$.

Age and disability. The effect of discrimination based on disability, $b=-.646 ; p<.001$, had a greater negative effect, $z=51.3635, p<.001$, on the HWB of disabled people over 65 years old compared to the effect of being discriminated based on age, $b=-0.327 ; p<.001$.

Ethnicity and disability. The effect of discrimination based on disability, $b=-.438$; $p=$ .003 , had a greater negative effect, $z=11.1559, p<.001$, on the HWB of disabled people belonging to a minority ethnic group compared to the effect of being discriminated based on ethnicity, $b=-.217 ; p<.001$,

Gender, age and disability. The effect of discrimination based on disability, $b=-.630 ; p$ $<.001$, had a greater negative effect, $z=38.1461, p<.001$, on the HWB of disabled women over 65 years old compared to the effect of being discriminated based on age, $b=-0.324 ; p<.001$. Discrimination based on gender was not statistically significant, $b=-.072 ; p=.726$.

Gender, ethnicity and disability. The effect of discrimination based on disability, $b=$ $.703 ; p=.012$, had a greater negative effect, $z=24.1525, p<.001$, on the HWB of disabled women belonging to a minority ethnic group compared to the effect of being discriminated based on ethnicity, $b=-.153 ; p=.043$. Discrimination based on gender was not statistically significant, $b=-.400 ; p=.154$

In all five combinations of multiple social categories, the effect of discrimination based on disability had a greater magnitude when compared to the effect of discrimination based on gender, age, or ethnicity. 


\section{Additional Analyses}

To account for the possibility that the reported effects could be due to disabled people having worse health, we tested our model in Analysis 1, but this time controlling for health when assessing the effects of belonging to different disadvantaged groups on well-being. For the wellbeing measure, the ESS questions on happiness and life satisfaction were averaged in one variable (Spearman-Brown Coefficient $=.80$, with only one factor emerging and explaining 84\% of the variance $)^{4}$. The self-reported health measure was introduced as a predictor in our model. In this model, only discrimination based on age, $b=-.224 ; p<.001$, and race, $b=-.111 ; p=.009$, were statistically significant. However, compared to our proposed model, this model had a poor fit to the data (see Table 6), which could be due to the interdependence between health and wellbeing. This finding, in itself, highlights the importance of examining the effects of health and well-being together as we propose in our analyses and emphasizes the relevance of treating heath as an outcome of discrimination instead of a predictor. Moreover, note that in Analysis 1 we had controlled for whether individuals felt hampered in their daily activities as this could indicate the presence of ill health. Note also that, in Analysis 2, all individuals were disabled, so the fact that disabled individuals might have lower levels of health is irrelevant for this analysis and our results were still supported.

Overall, we believe that the argument suggesting that disabled people have inherently worse health (compared to the remaining sample) is supportive of an individual or medical approach and neglects the impact (and relevance) of social factors in disabled people’s lives. In our research, we followed the approach promoted in a large body of work examining effects of

\footnotetext{
${ }^{4}$ Results revealed the same pattern for all three variables in the comparisons between disability and age. The only exception was for happiness, a variable in which discrimination based on age had a higher magnitude than discrimination based on disability.
} 
discrimination on health and well-being (Pascoe \& Smart-Richman, 2009; Schmitt et al., 2014). If the health of social minorities is affected by social factors (e.g., discrimination, poor access to health services), we would expect the same for disabled people. The tendency of prior research to treat disability as an individual and medical factor has potentially obscured important aspects of how health is produced and maintained, undermining efforts to eliminate health disparities and the social factors interfering with these processes.

\section{Discussion}

Our results indicated that facing ableism is associated with lower health and well-being (HWB) and that this effect was greater when compared to the effect of being discriminated against because of other disadvantaged group memberships (e.g., sexism, racism). These effects were evident in analyses between individuals (i.e., Analysis 1, comparing the effects of individuals experiencing different types of group discrimination) and within individuals (i.e., Analysis 2, examining the case of disabled individuals belonging to multiple disadvantaged categories).

These effects may be due to the vulnerability of this specific group. Disabled people are more likely to endure social isolation, not only due to prejudice, but also due to environmental barriers, which in turn may result in a lack of social support. Disabled people are perhaps more likely to internalize that they are not as capable as other individuals and, for this reason, may be disposed to believe that some experiences of discrimination are justified. Research has shown that responses to discrimination could be undermined when discrimination is perceived as legitimate, resulting in lower group identification and reduced intentions to engage in collective action (Jetten et al., 2011). In contrast, perceiving that discrimination is illegitimate is associated with high self-esteem and empowerment (Rüsch, Lieb, Bohus, \& Corrigan, 2006). 
An interesting finding emerging from our analyses relates to the fact that group-based discrimination based on age (i.e., ageism) was also one of the most harmful forms of discrimination, emerging as the second type of discrimination most negatively related with health and well-being. Indeed, ableism and ageism share some similarities that might help us to understand in further detail the reasons that both groups face such harsh consequences. For example, older adults are also more vulnerable to social isolation and paternalism (assuming low competence and low agency of both groups). Both ableism and ageism incorporate biological normative beliefs, related to body uniformity, ability, independence and energy, which are used to justify ableist and ageist oppression (Overall, 2006). Another interesting similarity pertains to the fact that both groups seem to be somewhat heterogeneous. For instance, disabled people’s attitudes toward different groups of impairment could prevent them from forming a homogeneous and strong minority group identification (Deal, 2003). A number of factors related to the nature, duration, and type of disability have been associated with disability prejudice from disabled people (Harder et al., in press). Similarly, older people’s distancing themselves from ageist stereotypes and behaviors prevents them from becoming aware of discrimination against their group, and engaging in collective action against ageism (Minichiello, Browne, \& Kendig, 2000). In some cases, this heterogeneity may prevent disabled people and older adults from forming a strong minority group identification, which is critical for buffering the deleterious effects of discrimination (Branscombe et al., 1999), and mobilizing collective action on behalf of their group.

With this research, we unveil another side of our initial paradox: one of the largest disadvantaged groups - disabled people - is, despite receiving less societal and academic attention, one of the most affected by discrimination. Our results show the importance of 
addressing disability and ableism in social research - specifically, in social psychology - which has paid less attention to this issue than to discrimination faced by other disadvantaged groups (e.g., see the small number of studies addressing disability, 8, in Schmitt et al.'s (2014) metaanalysis, when compared to racism, sexism, and heterosexism, 211, 23, and 21, respectively).

\section{Limitations and Future Directions}

In the ESS, a low percentage of disabled people self-identified as being a member of a group discriminated by society and, in fact, low percentages were found across all disadvantaged groups. Only $7 \%$ of the total sample mentioned that they belonged to a group that is socially discriminated, suggesting that experiences of discrimination were perhaps underreported. One reason might be due to socially desirable responding that could have been enhanced by face-toface interviews. In addition, responses were binary (i.e., belonging or not belonging to a group discriminated against by society) and, perhaps, a Likert type scale tapping into perceptions of discrimination would be more sensitive to different experiences. In this study, we benefited from the large data set, but were restricted to the available data. For researchers designing their own studies, it could be fruitful to include a scale tapping into perceptions of personal discrimination given that in their meta-analysis, Schmitt and colleagues (2014) found larger effect sizes for perceptions of personal discrimination compared to group discrimination.

The data used in our analyses were cross-sectional and this prevented us from testing the causal direction of the proposed relationships. Furthermore, while our study offered the added value of testing our hypothesis with representative samples in a Europe-wide context, it limits more fine-grained analysis at the individual level that would require psychological variables missing from these surveys. An avenue for future research would be to test the effects of ableism in a smaller scale longitudinal survey, which could allow researchers to draw more confident 
conclusions about causality and to identify the psychological mechanisms leading to poor wellbeing and health outcomes.

\section{Implications for Social Policy}

Our findings have critical implications for social policy. This research shows the strong implications of the discrimination endured by disabled people, and addressing this issue is likely to require intervention in multiple layers of our societies. To produce much-needed social change, efforts should be directed at both social and individual levels.

At the social level, it is crucial to raise awareness of the plight of disabled people and to develop synergies challenging current stereotypes. This might be achieved, for example, with campaigns showing counter-stereotypical group members (Ramasubramanian, 2011). Another relevant effort, would be the promotion and endorsement of the social model of disability, given that this model creates awareness of structural discrimination, which in turn produces policy support among nondisabled people (Dirth \& Branscombe, 2017). Another potential intervention to reduce intergroup prejudice would be the promotion of positive intergroup contact (Allport, 1954; Brown \& Hewstone, 2005) through various activities and spaces designed to facilitate such contact. A meta-analysis with different outgroup targets found that intergroup contact reduces prejudice and that effects for physically and mentally disabled people were of larger-thanaverage and average size, respectively (Pettigrew \& Tropp, 2006).

At the individual level, efforts should be channeled toward a greater empowerment and resilience of disabled people by creating a positive disabled identity. The rejection-identification model (Branscombe et al., 1999) states that positive ingroup identification acts as a buffer of the negative effects of perceived discrimination, protecting self-esteem. More recent research found that a disability identity was associated with higher self-esteem (Bogart, Lund, \& Rottenstein, 
2018; Cooper, Smith, \& Russell, 2017; Nario-Redmond, Noel, \& Fern, 2012), satisfaction with life (Bogart, 2014), increased social support, stereotype rejection and stigma resistance (Crabtree, Haslam, Postmes, \& Haslam, 2010), greater use of collective strategies (NarioRedmond et al., 2012; Nario-Redmond \& Oleson, 2016), and lower psychological distress (Bogart, 2015). Another potential path for interventions is to address the perceived legitimacy of some experiences. As we argued, perceived legitimacy could be related to the recognition of ableist behaviors, and research has found that perceiving discrimination as illegitimate is associated with high self-esteem and empowerment (Rüsch et al., 2006). Therefore, it is important to address perceived legitimacy of discrimination and promote awareness about what is discrimination/ableism. It is critical to show that this form of treatment is not justified, and to provide means of reporting any instances to legal authorities. This could perhaps be achieved by promoting the social model given that this model is associated with the perception of discrimination as illegitimate (Dirth \& Branscombe, in press). Moreover, given that disability intersects with other social categories, it is important to take an intersectional perspective to address disability and ableism (for a social justice framework, see Liasidou, 2013). Overall, to ensure self-determination and empowerment of disabled people, it is of paramount importance to address social policies in coordination with the organizations representing disabled people, to meet the moto "nothing about us, without us" (Charlton, 1998).

\section{Summary}

This study shows that ableism is associated with lower health and well-being, and that this effect has a greater magnitude when compared to the effects of being discriminated against because of other disadvantaged group memberships (e.g., sexism, racism). Our findings show that the quality of life of disabled people can no longer be ignored. It is imperative for academics 
and policy makers to work in tandem with the organizations of disabled people and governements to ensure that, accordingly the CRPD, "States Parties shall prohibit all discrimination on the basis of disability and guarantee to persons with disabilities equal and effective legal protection against discrimination on all grounds” (UN, 2006, art. 5, p. 7). 


\section{References}

Allport, G. W. (1954). The nature of prejudice. Cambridge/Reading, MA: Addison-Wesley.

Bogart, K. R. (2014). The role of disability self-concept in adaptation to congenital or acquired disability. Rehabilitation Psychology, 59, 107-115. http://doi.org/10.1037/a0035800

Bogart, K. R. (2015). Disability identity predicts lower anxiety and depression in multiple sclerosis. Rehabilitation Psychology, 60, 105-109. http://doi.org/10.1037/rep0000029

Bogart. K. R. \& Dunn, D. S. (in press). Ableism Special Issue Introduction. Journal of Social Issues.

Bogart, K. R., Lund, E. M., \& Rottenstein, A. (2018). Disability pride protects self-esteem through the rejection-identification model. Rehabilitation Psychology, 63, 155-159. http://doi.org/http://dx.doi.org/10.1037/rep0000166

Branscombe, N. R., Schmitt, M. T., \& Harvey, R. D. (1999). Perceiving pervasive discrimination among African Americans: Implications for group identification and well-being. Journal of Personality and Social Psychology, 77, 135-149.

Brisenden, S. (1986). Independent living and the medical model of disability. Disability, Handicap \& Society, 1, 173-178.

Brown, R., \& Hewstone, M. (2005). An integrative theory of intergroup contact. Advances in Experimental Social Psychology, 37, 255-343.

Campbell, F. A. K. (2001). Inciting Legal Fictions - Disability’s Date with Ontology and the Abieist Body of the Law. Griffith Law Review, 10, 42-62.

Campbell, F. A. K. (2008). Exploring internalized ableism using critical race theory. Disability and Society, 23, 151-162.

Charlton, J. I. (1998). Nothing about us without us: Disability oppression and empowerment. 
Berkeley: University of California Press.

Clark, A. E., \& Oswald, A. J. (1994). Unhappiness and unemployment. The Economic Journal, 104, 648-659.

Cole, E. R. (2009). Intersectionality and research in psychology. American Psychologist, 64, 170-180. http://dx.doi.org/10.1037/a0014564

Cooper, K., Smith, L. G. E., \& Russell, A. (2017). Social identity, self-esteem, and mental health in autism. European Journal of Social Psychology, 47, 844-854. http://doi.org/10.1002/ejsp.2297

Crabtree, J. W., Haslam, S. A., Postmes, T., \& Haslam, C. (2010). Mental health support groups, stigma, and self-Esteem: Positive and negative implications of group identification. Journal of Social Issues, 66, 553-569. http://doi.org/10.1111/j.1540-4560.2010.01662.x

Cuddy, A. J., Fiske, S. T., \& Glick, P. (2008). Warmth and competence as universal dimensions of social perception: The stereotype content model and the BIAS map. Advances in experimental social psychology, 40, 61-149.

Deal, M. (2003). Disabled people's attitudes toward other impairment groups: a hierarchy of impairments. Disability \& society, 18(7), 897-910.

Dirth, T. P., \& Branscombe, N. R. (2017). Disability models affect disability policy support through awareness of structural discrimination. Journal of Social Issues, 73, 413-442. http://doi.org/https://doi.org/10.1111/josi.12224

Dirth, T. P., \& Branscombe, N. R. (in press). Recognizing ableism: A social identity analysis of disabled people perceiving discrimination as illegitimate. Journal of Social Issues.

Dovidio, J. F., Pagotto, L., \& Hebl, M. R. (2011). Implicit attitudes and discrimination against people with physical disabilities. In R. L. Wiener \& S. L. Willborn (Eds.), Disability and 
aging discrimination (pp. 157-183). New York, NY: Springer. DOI: 10.1007/978-1-44196293-5_3

Dunn, D. (2015). Social Psychology of Disability. New York: Oxford University Press.

Dunn, D. S., \& Andrews, E. E. (2015). Person-first and identity-first language: Developing psychologists’ cultural competence using disability language. American Psychologist, 70, 255-264. http://doi.org/10.1037/a0038636

Dunn, O. J., \& Clark, V. (1969). Correlation coefficients measured on the same individuals. Journal of the American Statistical Association, 64, 366-377.

European Network on Independent Living. (2018). European Disability Movement Agrees Definition of Independent Living. Retrieved from http://enil.eu/news/european-disabilitymovement-agrees-definition-of-independent-living/

Fairbrother, M. (2014). Two multilevel modeling techniques for analyzing comparative longitudinal survey datasets. Political Science Research Methods 2,119-140.

Fiske, S. T., Cuddy, A. J. C., Glick, P., \& Xu, J. (2002). A model of (often mixed) stereotype content: Competence and warmth respectively follow from perceived status and competition. Journal of Personality and Social Psychology, 82, 878-902.

Fiske, S. T., Xu, J., Cuddy, A. C., \& Glick, P. (1999). (Dis)respecting versus (dis)liking: Status and interdependence predict ambivalent stereotypes of competence and warmth. Journal of Social Issues, 55, 473-489.

Goffman, E. (2006). Selections froms stigma. In L. J. Davis (Ed.), The disability studies reader (pp. 131-140). New York: Routledge.

Harder, J. A., Keller, V. N., \& Chopik, W. J. (in press). Demographic, Experiential, and Temporal Variation in Ableism. Journal of Social Issues. 
Harris, L. T., \& Fiske, S. T. (2006). Dehumanizing the Lowest of the Low Neuroimaging Responses to Extreme Out-Groups. Psychological Science, 17, 847-853.

Jetten, J., Schmitt, M. T., Branscombe, N. R., Garza, A. A., \& Mewse, A. J. (2011). Group commitment in the face of discrimination: The role of legitimacy appraisals. European Journal of Social Psychology, 41, 116-126. http://doi.org/10.1002/ejsp.743

Kahneman, D., \& Sugden, R. (2005). Experienced utility as a standard of policy evaluation. Environmental and Resource Economics, 32, 161-181.

Kavanagh, A. M., Krnjacki, L., Aitken, Z., Lamontagne, A. D., Beer, A., Baker, E., \& Bentley, R. (2015). Intersections between disability, type of impairment, gender and socio-economic disadvantage in a nationally representative sample of 33,101 working-aged Australians. Disability and Health Journal, 8, 191-199. http://doi.org/10.1016/j.dhjo.2014.08.008

Liasidou, A. (2013). Intersectional understandings of disability and implications for a social justice reform agenda in education policy and practice. Disability \& Society, 28, 299-312. http://doi.org/10.1080/09687599.2012.710012

Linton, S. (2006). Reassigning meaning. In L. J. Davis (Ed.), The disability studies reader (pp. 161-172). New York: Routledge.

Little, R. J., \& Rubin, D. B. (2000). Causal effects in clinical and epidemiological studies via potential outcomes: concepts and analytical approaches. Annual Review of Public Health, $21,121-145$.

Livneh, H. (1982). On the origins of negative attitudes towards people with disabilities. Rehabilitation Literature, 43, 338-347.

Livneh, H. (1988). A dimensional perspective on the origin of negative attitudes toward persons with disabilities. In H. E. Yuker (Ed.), Attitudes toward persons with disabilities (pp. 35- 
46). New York, NY: Springer.

Marmot, M., Allen, J., Bell, R., Bloomer, E., \& Goldblatt, P. (2012). WHO European review of social determinants of health and the health divide. The Lancet, 380, 1011-1029. http://doi.org/10.1016/S0140-6736(12)61228-8

Massey, D. S. \& Denton, N. A. (1988). The dimensions of residential segregation. Social Forces, 67, 281-315.

Minichiello, V., Browne, J., \& Kendig, H. (2000). Perceptions and consequences of ageism: views of older people. Ageing \& Society, 20(3), 253-278.

Nario-Redmond, M. R. (2010). Cultural stereotypes of disabled and non-disabled men and women: Consensus for global category representations and diagnostic domains. British Journal of Social Psychology, 49, 471-488. http://doi.org/10.1348/014466609X468411

Nario-Redmond, M. R., Kemerling, A. A., \& Silverman, A. (in press). Hostile, Benevolent and Ambivalent Ableism: Contemporary Manifestations. Journal of Social Issues.

Nario-Redmond, M. R., Noel, J. G., \& Fern, E. (2012). Redefining disability, re-imagining the self: Disability identification predicts self-esteem and strategic responses to stigma. Self and Identity, 1, 468-488. http://doi.org/10.1080/15298868.2012.681118

Nario-Redmond, M. R., \& Oleson, K. C. (2016). Disability Group Identification and DisabilityRights Advocacy. Emerging Adulthood, 4, 207-218. http://doi.org/10.1177/2167696815579830

Oliver, M. (1983). Social work with disabled people. Basingstoke, UK: Macmillan

Oliver, M., Sapey, B., \& Thomas, P. (2012). Social work with disabled people (1 $1^{\text {st }}$ ed.). UK: Palgrave Macmillan.

Oliver, M., \& Barnes, C. (2010). Disability studies, disabled people and the struggle for 
inclusion. British Journal of Sociology of Education, 31, 547-560.

http://doi.org/10.1080/01425692.2010.500088

Olkin, R., Hayward, H., Schaff, M. \& VanHeel, H. (in press). The experiences of microaggressions against women with visible and invisible disabilities. Journal of Social Issues.

Olkin, R., \& Pledger, C. (2003). Can disability studies and psychology join hands? American Psychologist, 58, 296-304.

Overall, C. (2006). Old age and ageism, impairment and ableism: Exploring the conceptual and material connections. NWSA Journal, 18, 126-137.

Pascoe, E., \& Smart-Richman, L. (2009). Perceived discrimination and health: A meta-analytic review. Psychological Bulletin, 135, 531-554.

Pettigrew, T. F., \& Tropp, L. R. (2006). A meta-analytic test of intergroup contact theory. Journal of Personality and Social Psychology, 90, 751-783.

Ramasubramanian, S. (2011). The impact of stereotypical versus counterstereotypical media exemplars on racial attitudes, causal attributions, and support for affirmative action. Communication Research, 38, 497-516. http://doi.org/10.1177/0093650210384854

Ramos, M. R., Cassidy, C., Reicher, S., \& Haslam, S. A. (2012). A longitudinal investigation of the rejection-identification hypothesis. British Journal of Social Psychology, 51, 642-660. http://doi.org/10.1111/j.2044-8309.2011.02029.x

Reichard, A., Stolzle, H., \& Fox, M. H. (2011). Health disparities among adults with physical disabilities or cognitive limitations compared to individuals with no disabilities in the United States. Disability and Health Journal, 4, 59-67. http://doi.org/10.1016/j.dhjo.2010.05.003 
Rohmer, O., \& Louvet, E. (2009). Describing persons with disability: Salience of disability, gender, and ethnicity. Rehabilitation Psychology, 54, 76-82.

Rohmer, O., \& Louvet, E. (2012). Implicit measures of the stereotype content associated with disability. British Journal of Social Psychology, 51, 732-740. http://doi.org/10.1111/j.20448309.2011.02087.x

Rüsch, N., Lieb, K., Bohus, M., \& Corrigan, P. W. (2006). Perceived legitimacy of discrimination among women with mental illness. Psychiatric Services, 57, 399-402.

Schmitt, M. T., Postmes, T., Branscombe, N. R., \& Garcia, A. (2014). The consequences of perceived discrimination for psychological well-being: A meta-analytic review. Psychological Bulletin, 140, 921-948. DOI: 10.1037/a0035754

Shakespeare, T. (1996). Disability, identity and difference. In C. Barnes \& G. Mercer (Eds.), Exploring the divide, (pp. 94-113). Leeds, UK: The Disability Press.

Stephens-Davidowitz, S. (2014). The cost of racial animus on a black candidate: Evidence using Google search data. Journal of Public Economics, 118, 26-40. http://doi.org/10.1016/j.jpubeco.2014.04.010

United Nations. (2006). Convention on the Rights of Persons with Disabilities. Treaty Series, 2515, 3.

United Nations. (2015). Global status report on disability and development. United Nations: New York. Retrieved from http://www.un.org/esa/socdev/documents/disability/2016/GlobalStatusReportonDisabilityan dDevelopment.pdf

Vilchinsky, N., Findler, L., \& Werner, S. (2010). Attitudes toward people with disabilities: The perspective of attachment theory. Rehabilitation Psychology, 55, 298-306. 
http://doi.org/http://dx.doi.org/10.1037/a0020491

Wang, K., Walker, K., Pietri, E., \& Ashburn-Nardo. L. (in press). Consequences of confronting patronizing help for people with disabilities: Do target gender and disability type matter? Journal of Social Issues.

Wilkinson, R. G., \& Marmot, M. (2003). Social determinants of health: the solid facts. Denmark: World Health Organization.

Wilson, M. C., \& Scior, K. (2014). Attitudes towards individuals with disabilities as measured by the Implicit Association Test: A literature review. Research in Developmental Disabilities, 35, 294-321. http://doi.org/10.1016/j.ridd.2013.11.003

World Health Organization. (2005). Constitution of the World Health Organization: Amendments to articles 24 and 25, adopted by the fifty-first World Health Assembly at Geneva May 16, 1998. Washington, D.C.: U.S. Dept. of State.

World Health Organization. (2011). World report on disability. WHO Press: Geneva. Retrieved from www.who.int/disabilities/world_report 


\section{Short biographies}

Carla Branco is a Ph.D. student in Social Psychology, at ISCTE-University Institute of Lisbon, Portugal. She studies the impact of social and socio-psychological determinants on the health and well-being of disabled people. As a disabled woman, she participates in the Center of Independent Living, in Portugal, and in the Youth Network of European Network on Independent Living.

Miguel R. Ramos is a Postdoctoral Research Associate at the Department of Experimental Psychology, University of Oxford, U.K. He received his PhD from the University of St. Andrews, U.K. His research investigates the impact of stereotyping and discrimination on disadvantaged groups.

Miles Hewstone is Professor of Social Psychology and Public Policy, and Fellow of New College, Oxford University, UK. He has published extensively on a wide range of topics in social psychology, focusing recently on prejudice and stereotyping, intergroup contact, and the reduction of intergroup conflict. He is a Fellow of the British Academy. 
Table 1

Sample Socioeconomic Information by Country

\begin{tabular}{|c|c|c|c|c|c|c|c|c|c|c|c|}
\hline \multirow[b]{2}{*}{ Variables } & \multicolumn{11}{|c|}{ Country } \\
\hline & 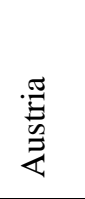 & 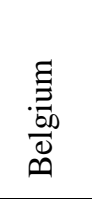 & 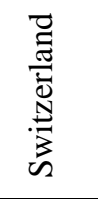 & 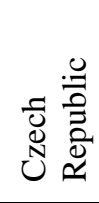 & 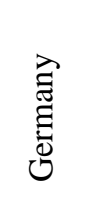 & 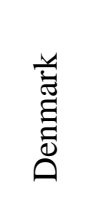 & 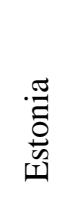 & $\begin{array}{l}\text { 䒕 } \\
\text { के }\end{array}$ & $\underset{\vec{\Xi}}{\vec{\Xi}}$ & 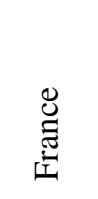 & 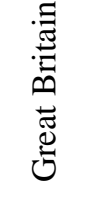 \\
\hline$N$ & 402 & 726 & 532 & 468 & 804 & 394 & 892 & 524 & 958 & 1265 & 1848 \\
\hline \multicolumn{12}{|l|}{ Sex $(\%)$} \\
\hline Male & 51 & 55 & 46 & 45 & 52 & 49 & 44 & 52 & 44 & 47 & 49 \\
\hline Female & 49 & 45 & 54 & 55 & 48 & 51 & 56 & 48 & 56 & 53 & 51 \\
\hline \multicolumn{12}{|l|}{ Age (years) } \\
\hline$M$ & 41.6 & 43.4 & 41.8 & 51.2 & 41.1 & 45.2 & 46.6 & 38.5 & 46.6 & 42.9 & 47.0 \\
\hline$S D$ & 17.1 & 17.0 & 14.8 & 16.5 & 15.1 & 16.0 & 17.1 & 14.0 & 17.8 & 15.4 & 16.7 \\
\hline \multicolumn{12}{|l|}{ Education (years) } \\
\hline$M$ & 12.8 & 12.8 & 12.3 & 12.3 & 13.5 & 13.4 & 13.0 & 13.4 & 13.2 & 13.0 & 13.9 \\
\hline$S D$ & 4.0 & 4.1 & 4.1 & 2.5 & 3.8 & 4.9 & 3.1 & 6.2 & 4.3 & 4.0 & 4.1 \\
\hline \multicolumn{12}{|l|}{ Born in country (\%) } \\
\hline Yes & 71 & 75 & 62 & 96 & 76 & 77 & 62 & 75 & 93 & 81 & 86 \\
\hline No & 29 & 25 & 38 & 4 & 24 & 23 & 38 & 25 & 7 & 19 & 14 \\
\hline \multicolumn{12}{|c|}{ Belong to minority ethnic group (\%) } \\
\hline Yes & 25 & 24 & 36 & 14 & 25 & 21 & 69 & 20 & 6 & 14 & 19 \\
\hline No & 75 & 76 & 64 & 86 & 75 & 79 & 31 & 80 & 94 & 86 & 81 \\
\hline \multicolumn{12}{|l|}{ Hampered (\%) } \\
\hline Yes & 32 & 30 & 29 & 52 & 39 & 44 & 28 & 15 & 48 & 33 & 33 \\
\hline No & 68 & 70 & 71 & 48 & 61 & 56 & 72 & 85 & 52 & 67 & 67 \\
\hline \multicolumn{12}{|l|}{ Belonging to a religion (\%) } \\
\hline Yes & 62 & 54 & 55 & 29 & 52 & 61 & 52 & 62 & 57 & 50 & 54 \\
\hline No & 38 & 46 & 45 & 71 & 48 & 39 & 48 & 38 & 43 & 50 & 46 \\
\hline \multicolumn{12}{|l|}{ Marital status (\%) } \\
\hline Married & 33 & 47 & 46 & 49 & 41 & 45 & 52 & 44 & 44 & 35 & 44 \\
\hline Separated & 2 & 2 & 2 & 1 & 1 & 2 & 1 & 2 & 1 & 1 & 3 \\
\hline Divorced & 12 & 12 & 10 & 16 & 12 & 12 & 14 & 5 & 15 & 15 & 13 \\
\hline Widowed & 8 & 4 & 3 & 17 & 3 & 4 & 9 & 2 & 5 & 4 & 6 \\
\hline Never married & 45 & 34 & 38 & 18 & 43 & 36 & 24 & 47 & 35 & 44 & 34 \\
\hline \multicolumn{12}{|l|}{ Employment status (\%) } \\
\hline Employed & 82 & 85 & 85 & 91 & 89 & 91 & 92 & 87 & 85 & 91 & 86 \\
\hline Self-employed & 16 & 14 & 13 & 9 & 10 & 8 & 7 & 12 & 13 & 8 & 12 \\
\hline $\begin{array}{r}\text { Working for own family } \\
\text { business }\end{array}$ & 1 & 1 & 2 & 1 & 1 & 1 & 1 & 1 & 2 & 0 & 1 \\
\hline \multicolumn{12}{|l|}{ Ever unemployed (\%) } \\
\hline Yes & 40 & 42 & 34 & 37 & 50 & 47 & 40 & 50 & 46 & 52 & 34 \\
\hline No & 60 & 58 & 66 & 63 & 50 & 53 & 60 & 50 & 54 & 48 & 66 \\
\hline \multicolumn{12}{|c|}{ Feeling about household's present income (\%) } \\
\hline Living comfortably & 17 & 25 & 37 & 7 & 16 & 46 & 6 & 24 & 16 & 19 & 30 \\
\hline Coping & 49 & 41 & 36 & 29 & 46 & 37 & 44 & 39 & 53 & 48 & 44 \\
\hline Difficult & 22 & 24 & 18 & 35 & 26 & 12 & 32 & 25 & 21 & 26 & 19 \\
\hline Very difficult & 12 & 10 & 9 & 30 & 11 & 5 & 19 & 12 & 10 & 7 & 7 \\
\hline
\end{tabular}


Table 1 (continued)

\begin{tabular}{|c|c|c|c|c|c|c|c|c|c|c|c|}
\hline \multirow[b]{2}{*}{ Variables } & \multicolumn{11}{|c|}{ Country } \\
\hline & $\begin{array}{l}\vec{D} \\
\text { 总 } \\
\text { 胥 }\end{array}$ & 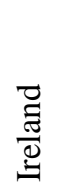 & $\underset{\tilde{\Xi}}{\tilde{\Xi}}$ & $\begin{array}{l}\text { 畓 } \\
\text { 壱 } \\
\text { 莺 }\end{array}$ & 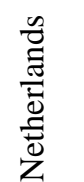 & 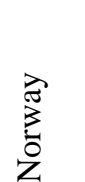 & $\begin{array}{l}\text { 范 } \\
\frac{0}{0}\end{array}$ & 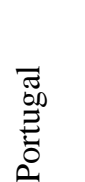 & 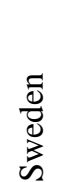 & $\begin{array}{l}. \frac{\pi}{\tilde{D}} \\
\frac{\overrightarrow{0}}{\omega}\end{array}$ & 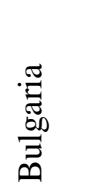 \\
\hline$N$ & 567 & 639 & 1683 & 196 & 944 & 616 & 497 & 343 & 920 & 267 & 551 \\
\hline \multicolumn{12}{|l|}{ Sex (\%) } \\
\hline Male & 49 & 50 & 50 & 37 & 45 & 51 & 50 & 42 & 36 & 51 & 42 \\
\hline Female & 51 & 50 & 50 & 63 & 55 & 49 & 50 & 58 & 64 & 49 & 58 \\
\hline \multicolumn{12}{|l|}{ Age (years) } \\
\hline$M$ & 41.8 & 41.5 & 39.4 & 52.1 & 43.5 & 42.0 & 43.8 & 44.2 & 43.8 & 41.3 & 49.2 \\
\hline$S D$ & 15.2 & 15.6 & 16.1 & 17.2 & 16.1 & 16.0 & 16.7 & 17.2 & 17.9 & 15.9 & 16.5 \\
\hline \multicolumn{12}{|l|}{ Education (years) } \\
\hline$M$ & 10.8 & 14.1 & 13.3 & 13.1 & 13.4 & 13.8 & 12.4 & 8.8 & 13.5 & 12.6 & 10.0 \\
\hline$S D$ & 4.1 & 4.3 & 3.9 & 3.1 & 4.2 & 4.1 & 3.6 & 4.6 & 3.7 & 3.8 & 3.9 \\
\hline \multicolumn{12}{|l|}{ Born in country (\%) } \\
\hline Yes & 97 & 69 & 83 & 92 & 77 & 82 & 99 & 62 & 79 & 90 & 99 \\
\hline No & 3 & 31 & 17 & 8 & 23 & 18 & 1 & 38 & 21 & 10 & 1 \\
\hline \multicolumn{12}{|c|}{ Belong to minority ethnic group (\%) } \\
\hline Yes & 43 & 18 & 46 & 25 & 27 & 16 & 3 & 21 & 13 & 9 & 50 \\
\hline No & 57 & 82 & 54 & 75 & 73 & 84 & 97 & 79 & 87 & 91 & 50 \\
\hline \multicolumn{12}{|l|}{ Hampered (\%) } \\
\hline Yes & 40 & 24 & 16 & 56 & 43 & 39 & 45 & 27 & 42 & 43 & 27 \\
\hline No & 60 & 76 & 84 & 44 & 57 & 61 & 55 & 73 & 58 & 57 & 73 \\
\hline \multicolumn{12}{|l|}{ Belonging to a religion (\%) } \\
\hline Yes & 56 & 66 & 95 & 88 & 45 & 57 & 84 & 72 & 36 & 60 & 83 \\
\hline No & 44 & 34 & 5 & 12 & 55 & 43 & 16 & 28 & 64 & 40 & 17 \\
\hline \multicolumn{12}{|l|}{ Marital status (\%) } \\
\hline Married & 48 & 39 & 62 & 49 & 40 & 39 & 53 & 41 & 36 & 48 & 51 \\
\hline Separated & 1 & 8 & 0 & 0 & 1 & 2 & 2 & 3 & 1 & 0 & 1 \\
\hline Divorced & 15 & 5 & 7 & 16 & 13 & 10 & 6 & 8 & 14 & 5 & 9 \\
\hline Widowed & 6 & 5 & 3 & 18 & 5 & 3 & 9 & 9 & 4 & 3 & 14 \\
\hline Never married & 30 & 44 & 28 & 17 & 42 & 46 & 30 & 39 & 45 & 44 & 24 \\
\hline \multicolumn{12}{|l|}{ Employment status (\%) } \\
\hline Employed & 94 & 85 & 84 & 97 & 87 & 88 & 82 & 83 & 90 & 90 & 94 \\
\hline Self-employed & 5 & 14 & 15 & 2 & 12 & 11 & 16 & 16 & 9 & 5 & 5 \\
\hline $\begin{array}{r}\text { Working for own family } \\
\text { business }\end{array}$ & 1 & 1 & 1 & 1 & 1 & 1 & 2 & 1 & 1 & 5 & 2 \\
\hline \multicolumn{12}{|l|}{ Ever unemployed (\%) } \\
\hline Yes & 52 & 45 & 28 & 31 & 38 & 31 & 41 & 45 & 36 & 36 & 65 \\
\hline No & 48 & 55 & 72 & 69 & 62 & 69 & 59 & 55 & 64 & 64 & 35 \\
\hline \multicolumn{12}{|c|}{ Feeling about household's present income (\%) } \\
\hline Living comfortably & 2 & 17 & 15 & 10 & 29 & 44 & 6 & 5 & 41 & 28 & 1 \\
\hline Coping & 22 & 40 & 40 & 41 & 41 & 37 & 40 & 34 & 38 & 49 & 12 \\
\hline Difficult & 29 & 24 & 27 & 27 & 21 & 13 & 45 & 32 & 16 & 15 & 20 \\
\hline Very difficult & 47 & 18 & 18 & 22 & 8 & 5 & 10 & 29 & 5 & 8 & 67 \\
\hline
\end{tabular}


Table 1 (continued)

\begin{tabular}{|c|c|c|c|c|c|c|c|c|c|c|}
\hline Variable & $\underset{\tilde{D}}{\stackrel{D}{\Delta}}$ & 芯 & 氶 & $\frac{\vec{\pi}}{ \pm}$ & 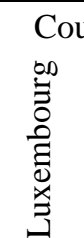 & 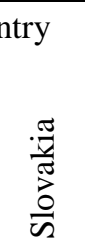 & 哭 & 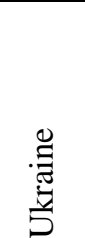 & $\begin{array}{l}0 \\
0 \\
0 \\
0 \\
0 \\
1\end{array}$ & 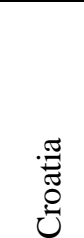 \\
\hline$N$ & 166 & 495 & 165 & 64 & 110 & 315 & 338 & 259 & 626 & 86 \\
\hline \multicolumn{11}{|l|}{ Sex (\%) } \\
\hline Male & 39 & 43 & 37 & 61 & 51 & 43 & 46 & 43 & 39 & 55 \\
\hline Female & 61 & 57 & 63 & 39 & 49 & 57 & 54 & 57 & 61 & 45 \\
\hline \multicolumn{11}{|l|}{ Age (years) } \\
\hline$M$ & 41.3 & 42.4 & 45.6 & 43.4 & 36.8 & 43.3 & 33.1 & 50.7 & 48.6 & 51.7 \\
\hline$S D$ & 16.4 & 16.4 & 16.9 & 15.4 & 13.4 & 16.0 & 12.1 & 17.9 & 18.2 & 16.4 \\
\hline \multicolumn{11}{|l|}{ Education (years) } \\
\hline$M$ & 12.5 & 10.6 & 14.8 & 13.0 & 12.5 & 12.2 & 7.5 & 12.3 & 12.4 & 11.8 \\
\hline$S D$ & 4.3 & 4.2 & 4.2 & 5.7 & 3.9 & 3.8 & 4.5 & 3.5 & 3.2 & 4.1 \\
\hline \multicolumn{11}{|l|}{ Born in country (\%) } \\
\hline Yes & 78 & 63 & 95 & 89 & 52 & 97 & 99 & 80 & 90 & 85 \\
\hline No & 22 & 37 & 5 & 11 & 48 & 3 & 1 & 20 & 10 & 15 \\
\hline \multicolumn{11}{|c|}{ Belong to minority ethnic group (\%) } \\
\hline Yes & 13 & 30 & 4 & 13 & 25 & 32 & 33 & 14 & 21 & 14 \\
\hline No & 87 & 70 & 96 & 88 & 75 & 68 & 67 & 86 & 79 & 86 \\
\hline \multicolumn{11}{|l|}{ Hampered (\%) } \\
\hline Yes & 27 & 20 & 33 & 23 & 29 & 32 & 19 & 63 & 51 & 43 \\
\hline No & 73 & 80 & 67 & 77 & 71 & 68 & 81 & 37 & 49 & 57 \\
\hline \multicolumn{11}{|l|}{ Belonging to a religion (\%) } \\
\hline Yes & 98 & 90 & 47 & 66 & 55 & 78 & 92 & 67 & 60 & 74 \\
\hline No & 2 & 10 & 53 & 34 & 45 & 22 & 8 & 33 & 40 & 26 \\
\hline \multicolumn{11}{|l|}{ Marital status (\%) } \\
\hline Marrie & 54 & 58 & 45 & 56 & 53 & 57 & 60 & 55 & 41 & 69 \\
\hline Separated & 0 & 1 & 6 & 2 & 3 & 0 & 1 & 1 & 1 & 0 \\
\hline Divorced & 11 & 5 & 10 & 5 & 5 & 6 & 2 & 9 & 18 & 5 \\
\hline Widowed & 5 & 8 & 6 & 2 & 3 & 8 & 4 & 21 & 20 & 11 \\
\hline Never married & 30 & 28 & 33 & 36 & 37 & 28 & 33 & 13 & 19 & 15 \\
\hline \multicolumn{11}{|l|}{ Employment status (\%) } \\
\hline Employed & 83 & 71 & 85 & 70 & 91 & 91 & 79 & 95 & 94 & 89 \\
\hline Self-employed & 12 & 28 & 12 & 26 & 9 & 7 & 18 & 3 & 5 & 7 \\
\hline $\begin{array}{r}\text { Working for own family } \\
\text { business }\end{array}$ & 6 & 1 & 3 & 4 & 0 & 2 & 3 & 2 & 1 & 4 \\
\hline \multicolumn{11}{|l|}{ Ever unemployed (\%) } \\
\hline Yes & 33 & 45 & 24 & 42 & 27 & 49 & 25 & 43 & 33 & 48 \\
\hline No & 67 & 55 & 76 & 58 & 73 & 51 & 75 & 57 & 67 & 52 \\
\hline \multicolumn{11}{|c|}{ Feeling about household’s present income (\%) } \\
\hline Living comfortably & 10 & 6 & 36 & 21 & 37 & 4 & 9 & 2 & 3 & 22 \\
\hline Coping & 32 & 25 & 33 & 49 & 35 & 33 & 44 & 12 & 25 & 38 \\
\hline Difficult & 35 & 34 & 18 & 24 & 14 & 32 & 28 & 39 & 39 & 20 \\
\hline Very difficult & 24 & 35 & 13 & 6 & 15 & 30 & 20 & 48 & 33 & 20 \\
\hline
\end{tabular}


Table 2

Percentages of Individuals Affirming that They Belong to a Group that is Discriminated in Society by Type of Discrimination and Country

\begin{tabular}{|c|c|c|c|c|c|c|c|c|c|}
\hline \multirow[b]{2}{*}{ Countries } & \multicolumn{9}{|c|}{ Group-based discrimination } \\
\hline & $\begin{array}{l}\frac{\tilde{0}}{0} \\
\dot{\tilde{u}} \\
\tilde{\ddot{n}} \\
\end{array}$ & 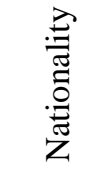 & 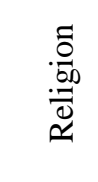 & 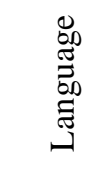 & 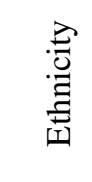 & $\stackrel{8}{\alpha}$ & 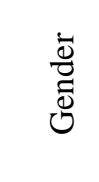 & 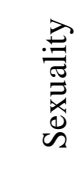 & 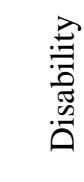 \\
\hline$N$ & 2754 & 3578 & 3278 & 2002 & 2421 & 2460 & 2021 & 944 & 1404 \\
\hline Austria & 8.7 & 23.9 & 15.9 & 12.4 & 8.7 & 10.7 & 15.2 & 11.2 & 4.7 \\
\hline Belgium & 18.7 & 18.3 & 23.1 & 9.9 & 5.9 & 6.6 & 4.5 & 5.9 & 7.4 \\
\hline Switzerland & 10.2 & 29.1 & 16.9 & 5.5 & 11.1 & 5.1 & 11.8 & 8.6 & 6.4 \\
\hline $\begin{array}{l}\text { Czech } \\
\text { Republic }\end{array}$ & 16.5 & 6.2 & 5.3 & 1.5 & 6.6 & 39.7 & 15.6 & 3.4 & 16.2 \\
\hline Germany & 5.6 & 22.9 & 13.1 & 10.0 & 13.8 & 5.7 & 9.0 & 9.0 & 9.1 \\
\hline Denmark & 17.0 & 11.9 & 20.3 & 7.1 & 11.9 & 10.7 & 5.3 & 5.1 & 9.6 \\
\hline Estonia & .1 & 55.5 & 2.0 & 59.3 & 3.6 & 12.7 & 6.8 & 1.5 & 4.8 \\
\hline Spain & 16.4 & 23.3 & 16.4 & 9.9 & 5.0 & 5.2 & 11.5 & 7.4 & 5.2 \\
\hline Finland & 2.5 & 3.0 & 7.6 & 9.5 & 2.9 & 15.8 & 7.7 & 4.9 & 5.9 \\
\hline France & 22.3 & 9.6 & 13.4 & 2.8 & 6.6 & 6.2 & 11.5 & 5.5 & 7.0 \\
\hline Great Britain & 25.7 & 14.7 & 22.3 & 2.2 & 8.9 & 16.6 & 13.4 & 7.6 & 6.9 \\
\hline Hungary & 34.9 & 18.7 & 6.0 & 1.8 & 34.9 & 15.2 & 3.5 & .7 & 8.3 \\
\hline Ireland & 11.4 & 19.2 & 14.9 & 2.8 & 6.3 & 12.4 & 11.6 & 5.8 & 7.8 \\
\hline Israel & 24.0 & 44.7 & 46.8 & 31.9 & 28.0 & 11.5 & 16.2 & 7.0 & 8.0 \\
\hline Lithuania & 1.0 & 6.1 & 6.6 & 13.8 & 12.8 & 46.9 & 6.6 & 3.6 & 13.8 \\
\hline Netherlands & 19.1 & 18.0 & 21.3 & 3.8 & 10.7 & 11.0 & 7.9 & 10.8 & 9.5 \\
\hline Norway & 7.8 & 8.6 & 18.3 & 3.1 & 11.5 & 6.7 & 11.5 & 6.2 & 11.5 \\
\hline Poland & .8 & 2.0 & 15.7 & 1.0 & 1.0 & 13.7 & 9.7 & 1.0 & 14.1 \\
\hline Portugal & 21.6 & 19.2 & 13.1 & 2.0 & 5.0 & 12.0 & 3.5 & 3.5 & 5.5 \\
\hline Sweden & 5.8 & 11.6 & 9.0 & 5.5 & 9.1 & 15.1 & 33.3 & 3.6 & 8.4 \\
\hline Slovenia & 5.6 & 3.4 & 19.5 & 2.6 & 15.7 & 9.7 & 10.5 & 5.2 & 15.4 \\
\hline Bulgaria & 10.9 & 6.9 & 7.8 & 5.6 & 43.6 & 31.4 & 5.4 & .4 & 7.6 \\
\hline Cyprus & 7.2 & 22.9 & 9.0 & 4.2 & 2.4 & 7.8 & 7.2 & 10.2 & 6.0 \\
\hline Greece & 15.2 & 37.8 & 10.9 & 6.1 & 4.2 & 14.1 & 10.3 & 2.6 & 3.6 \\
\hline Iceland & 1.8 & 1.8 & 3.0 & 1.2 & 2.4 & 16.4 & 24.8 & 1.8 & 8.5 \\
\hline Italy & 7.8 & 10.9 & 20.3 & 0.0 & 4.7 & 6.3 & 9.4 & 9.4 & 3.1 \\
\hline Luxembourg & 8.2 & 38.2 & 7.3 & 10.0 & 1.8 & 0.0 & 4.5 & 3.6 & 8.2 \\
\hline Slovakia & 23.8 & 15.2 & 4.4 & 4.8 & 20.0 & 20.3 & 9.2 & .6 & 7.3 \\
\hline Turkey & 6.8 & 16.3 & 24.9 & 25.7 & 23.7 & 14.8 & 4.7 & 2.7 & .6 \\
\hline Ukraine & 6.6 & 3.9 & 7.7 & 18.1 & 10.8 & 20.8 & 3.1 & .4 & 9.7 \\
\hline Kosovo & 5.4 & 4.8 & 8.3 & 4.0 & 22.0 & 31.3 & 7.7 & 3.0 & 12.6 \\
\hline
\end{tabular}



Croatia
0.0
5.8
9.3
0.0
$2.3 \quad 27.9$
7.0
1.2
12.8

Note. $N$ is the number of respondents that nominated each group-based discrimination. Percentages are relative to the number of respondents that nominated each group-based discrimination in each country (row). 
Table 3

Mean Health and Well-being (HWB) Scores by Type of Discrimination and Country

\begin{tabular}{|c|c|c|c|c|c|c|c|c|c|}
\hline \multirow[b]{2}{*}{ Countries } & \multicolumn{9}{|c|}{ Group-based discrimination } \\
\hline & 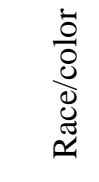 & 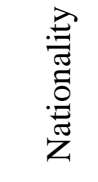 & 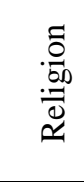 & 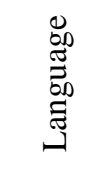 & 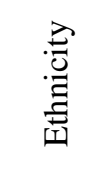 & $\stackrel{\infty}{\&}$ & 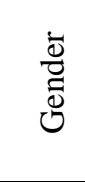 & 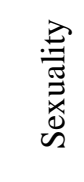 & 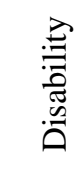 \\
\hline$M$ & 2.03 & 2.11 & 2.57 & 2.00 & 1.83 & 1.47 & 2.36 & 2.53 & 1.14 \\
\hline Austria & 2.56 & 2.30 & 2.23 & 2.37 & 2.59 & 1.84 & 2.09 & 2.39 & 1.84 \\
\hline Belgium & 2.35 & 2.47 & 2.62 & 2.65 & 2.53 & 2.19 & 2.72 & 2.66 & .98 \\
\hline Switzerland & 2.22 & 2.66 & 2.73 & 2.81 & 2.39 & 2.86 & 2.59 & 2.92 & .87 \\
\hline $\begin{array}{l}\text { Czech } \\
\text { Republic }\end{array}$ & 1.31 & 1.42 & .75 & 2.07 & 1.68 & 1.08 & 1.85 & 1.95 & .52 \\
\hline Germany & 1.72 & 2.20 & 2.31 & 2.21 & 2.13 & 1.50 & 2.06 & 2.23 & .84 \\
\hline Denmark & 2.88 & 3.01 & 2.95 & 2.75 & 3.10 & 2.85 & 2.66 & 2.90 & 1.66 \\
\hline Estonia & 1.55 & 1.42 & 1.70 & 1.45 & 1.69 & .77 & 1.84 & 2.93 & .10 \\
\hline Spain & 2.32 & 2.16 & 2.63 & 2.53 & 1.94 & 2.20 & 2.31 & 2.27 & 1.85 \\
\hline Finland & 2.90 & 2.48 & 3.20 & 3.08 & 2.60 & 2.50 & 2.66 & 2.78 & 2.17 \\
\hline France & 1.83 & 1.86 & 2.09 & 2.04 & 1.83 & 1.20 & 2.02 & 2.31 & 1.06 \\
\hline $\begin{array}{l}\text { Great } \\
\text { Britain }\end{array}$ & 2.34 & 2.23 & 2.66 & 2.29 & 2.24 & 2.27 & 2.49 & 2.70 & 1.34 \\
\hline Hungary & .79 & .80 & 1.59 & 1.04 & 1.00 & .09 & .77 & 1.98 & .08 \\
\hline Ireland & 2.11 & 2.32 & 2.72 & 2.69 & 2.08 & 2.13 & 2.05 & 2.24 & 1.53 \\
\hline Israel & 2.53 & 2.65 & 2.93 & 2.52 & 2.53 & 2.17 & 2.71 & 2.52 & 2.04 \\
\hline Lithuania & -1.92 & 1.80 & 1.55 & .95 & 1.64 & .79 & 1.41 & 1.88 & -.44 \\
\hline Netherlands & 2.60 & 2.55 & 2.84 & 2.24 & 2.53 & 2.20 & 2.62 & 2.79 & 1.54 \\
\hline Norway & 2.70 & 2.66 & 3.14 & 2.71 & 2.89 & 2.46 & 2.88 & 2.77 & 1.98 \\
\hline Poland & 2.20 & 1.11 & 2.29 & 1.96 & 2.95 & .85 & 1.80 & 1.35 & 1.20 \\
\hline Portugal & 1.92 & 1.90 & 1.70 & 1.93 & 1.38 & .77 & 2.17 & 1.93 & .36 \\
\hline Sweden & 2.33 & 2.62 & 2.89 & 2.56 & 2.36 & 2.38 & 2.78 & 2.93 & 1.83 \\
\hline Slovenia & 1.97 & 1.59 & 2.50 & 2.88 & 1.68 & 1.55 & 2.48 & 2.76 & .75 \\
\hline Bulgaria & -.26 & .27 & 1.06 & .49 & .25 & .03 & .33 & .51 & -.34 \\
\hline Cyprus & 1.86 & 1.72 & 2.92 & 1.66 & 2.37 & 2.33 & 1.52 & 2.21 & .57 \\
\hline Greece & 1.33 & 2.04 & 2.27 & 2.04 & 1.49 & 1.00 & 1.92 & 2.99 & .36 \\
\hline Iceland & 2.99 & 1.99 & 3.44 & 2.04 & 2.88 & 2.83 & 3.50 & 3.22 & 2.17 \\
\hline Italy & 2.48 & 1.65 & 2.46 & - & 3.07 & .63 & 2.68 & 2.18 & .43 \\
\hline Luxembourg & 2.04 & 2.33 & 2.28 & 2.91 & 2.28 & - & 3.38 & 3.23 & 1.46 \\
\hline Slovakia & 1.73 & 1.01 & 2.00 & 1.77 & 1.19 & .89 & 1.95 & 4.25 & 1.04 \\
\hline Turkey & .54 & .76 & 1.57 & .72 & .67 & .47 & 1.50 & 3.00 & -.04 \\
\hline Ukraine & 1.41 & 1.86 & 1.11 & .34 & .73 & -.30 & .44 & 1.22 & .11 \\
\hline Kosovo & 1.34 & .97 & 1.99 & 1.87 & 1.63 & .48 & 1.55 & .76 & .09 \\
\hline Croatia & - & 2.57 & 3.42 & - & .45 & 1.24 & 2.04 & 4.22 & -.48 \\
\hline
\end{tabular}


Note. HWB scores are standardized. Minimum value was -3 and maximum value was 7. Mean of HWB was 2.01 $(S D=1.708)$ in the sample of Analysis 1. 
Table 4

Effects of Group-based Discrimination between Individuals

\begin{tabular}{|c|c|c|c|}
\hline & \multirow[b]{2}{*}{ Variables } & \multicolumn{2}{|c|}{ Health and Well-being } \\
\hline & & Without control variables & With control variables \\
\hline \multirow{10}{*}{$\begin{array}{l}\text { Within level } \\
\text { coefficients }\end{array}$} & Discrimination based on: & & \\
\hline & Color or race & $-0.082(0.084)$ & $-0.063(0.079)$ \\
\hline & Nationality & $-0.028(0.543)$ & $-0.040(0.226)$ \\
\hline & Religion & $0.426(0.000)^{* * *}$ & $0.195(0.000)^{* * *}$ \\
\hline & Language & $-0.065(0.440)$ & $-0.022(0.706)$ \\
\hline & Ethnic group & $-0.096(0.153)$ & $-0.024(0.532)$ \\
\hline & Age & $-0.444(0.000) * * *$ & $-0.133(0.000) * * *$ \\
\hline & Gender & $0.276(0.000)^{* * *}$ & $0.007(0.800)$ \\
\hline & Sexuality & $0.354(0.000)^{* * *}$ & $0.126(0.010)^{*}$ \\
\hline & Disability & $-0.918(0.000)^{* * *}$ & $-0.267(0.000) * * *$ \\
\hline \multirow{24}{*}{$\begin{array}{l}\text { Within level } \\
\text { coefficients } \\
\text { (control } \\
\text { variables) }\end{array}$} & Sex (male) & - & $0.134(0.000)^{* * *}$ \\
\hline & Age & - & $-5.362(0.004)^{* *}$ \\
\hline & Education & - & $0.017(0.000)^{* * *}$ \\
\hline & Born in country & - & $-0.051(0.164)$ \\
\hline & Belong to minority ethnic group & - & $0.090(0.051)$ \\
\hline & Hampered & - & $-0.672(0.000) * * *$ \\
\hline & Belonging to a religion (no) & - & $-0.028(0.303)$ \\
\hline & Marital status: ref. married & & \\
\hline & Separated & - & $-0.594(0.000) * * *$ \\
\hline & Divorced & - & $-0.365(0.000) * * *$ \\
\hline & Widowed & - & $-0.403(0.000) * * *$ \\
\hline & Never married & - & $-0.280(0.000) * * *$ \\
\hline & Employment status: ref. employed & & \\
\hline & Self-employed & - & $-0.020(0.666)$ \\
\hline & Working for own family business & - & $-0.084(0.439)$ \\
\hline & Ever unemployed & - & $0.241(0.000)^{* * *}$ \\
\hline & $\begin{array}{l}\text { Feeling about household's income: ref. } \\
\text { coping on present income }\end{array}$ & & \\
\hline & Living comfortably on present income & - & $0.344(0.000)^{* * *}$ \\
\hline & Difficult on present income & - & $-0.466(0.000) * * *$ \\
\hline & Very difficult on present income & - & $-1.084(0.000) * * *$ \\
\hline & Socially meet & - & $0.101(0.000)^{* * *}$ \\
\hline & Take part in social activities & - & $0.165(0.000)^{* * *}$ \\
\hline & State of education & - & $0.052(0.000)^{* * *}$ \\
\hline & State of health services & - & $0.099(0.000)^{* * *}$ \\
\hline \multicolumn{2}{|c|}{ Unexplained variance } & $2.424(0.000)^{* * *}$ & $1.678(0.000)^{* * *}$ \\
\hline Between & Wave & - & $0.071(0.043)^{*}$ \\
\hline level & GDP (average) & - & $0.613(0.020)^{*}$ \\
\hline coefficients & GDP (change) & - & $-0.352(0.148)$ \\
\hline (control & Equality (average) & - & $0.671(0.204)$ \\
\hline \multirow[t]{3}{*}{ variables) } & Equality (change) & - & $1.512(0.191)$ \\
\hline & Life expectancy rate (average) & - & $0.028(0.202)$ \\
\hline & Life expectancy rate (change) & - & $-0.056(0.271)$ \\
\hline \multicolumn{2}{|c|}{ Unexplained variance } & $0.428(0.000)^{* * *}$ & $0.070(0.004)^{* *}$ \\
\hline \multirow[t]{3}{*}{ Fit indicators } & Loglikelihood & -43032.340 & -31439.821 \\
\hline & Akaike information criterion (AIC) & 86088.681 & 62959.643 \\
\hline & Bayesian inform. criterion (BIC) & 86185.185 & 63273.008 \\
\hline Sample & Countries; country-waves; & $36 ; 176 ;$ & $32 ; 166$ \\
\hline Size & Respondents & 22971 & 18660 \\
\hline
\end{tabular}


Note. Total sample changes between models, because variables are not available in all countries and respondents.

${ }^{*} p<.05 . * * p<.01 .{ }^{* * *} p<.001$. 
Table 5

Effects of Group-based Discrimination within Individuals

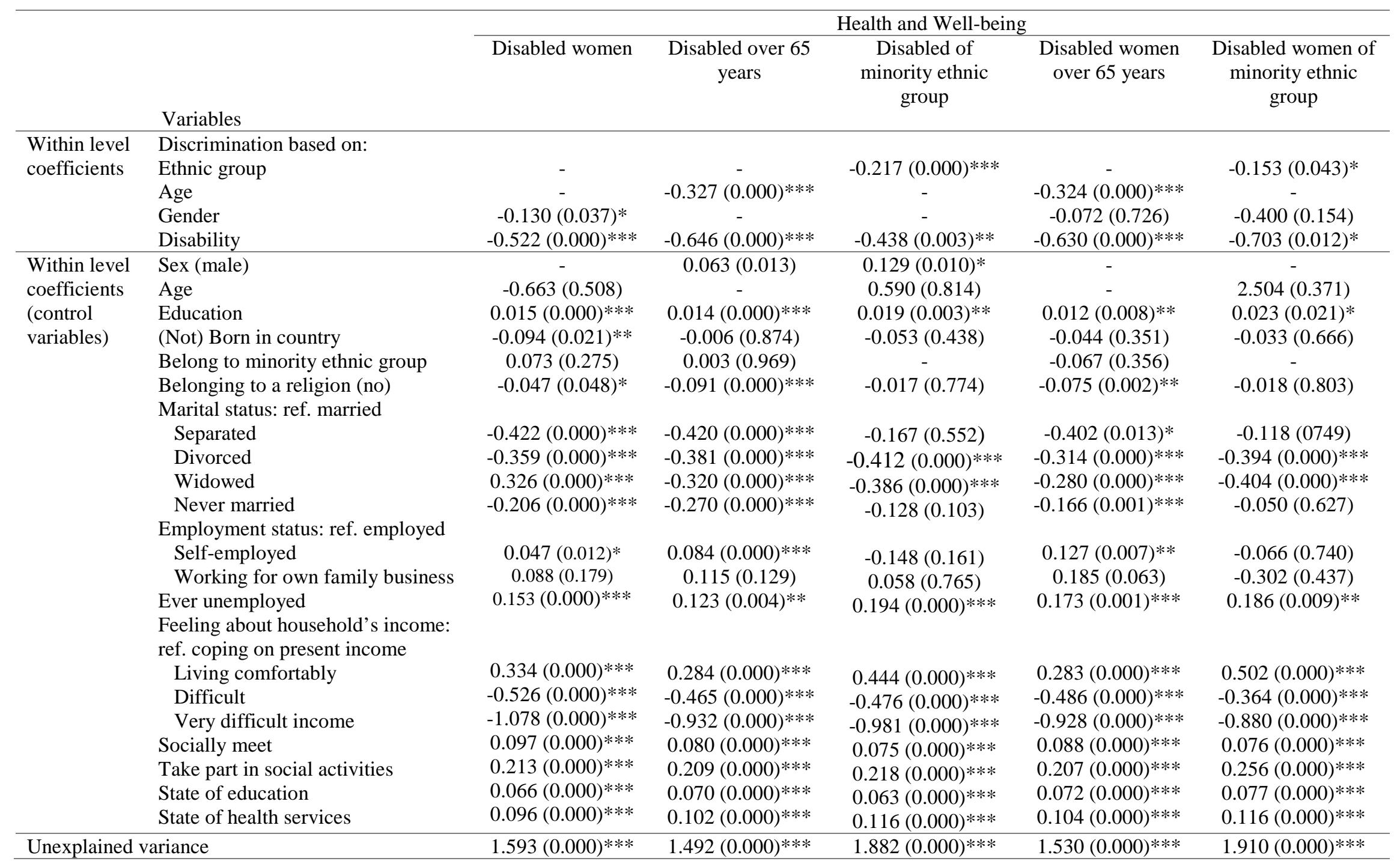


Table 5 (cont.)

\begin{tabular}{|c|c|c|c|c|c|c|}
\hline & Variables & \multicolumn{5}{|c|}{ Health \& Well-being } \\
\hline \multirow{5}{*}{$\begin{array}{l}\text { Between } \\
\text { level } \\
\text { coefficients } \\
\text { (control } \\
\text { variables) }\end{array}$} & Wave & $0.010(0.710)$ & $-0.016(0.532)$ & $0.090(0.045)^{*}$ & $-0.036(0.229)$ & $0.089(0.103)$ \\
\hline & GDP (change) & $-0.390(0.169)$ & $-0.280(0.273)$ & $-0.080(0.868)$ & $-0.106(0.733)$ & $0.006(0.992)$ \\
\hline & Equality (average) & $1.481(0.016)^{*}$ & $2.030(0.003)^{* *}$ & $1.105(0.077)$ & $2.613(0.000)^{* * *}$ & $0.582(0.508)$ \\
\hline & Equality (change) & $-0.231(0.787)$ & $0.116(0.849)$ & $3.770(0.157)$ & $-0.037(0.970)$ & $3.684(0.320)$ \\
\hline & Life expect. rate (average) & $0.027(0.147)$ & $0.033(0.125)$ & $0.024(0.326)$ & $0.029(0.194)$ & $0.023(0.495)$ \\
\hline \multirow[t]{3}{*}{ Fit indicators } & Loglikelihood & -64759.504 & -41708.230 & -6477.596 & -24938.668 & -3639.702 \\
\hline & Akaike information criterion (AIC) & 129581.008 & 83478.460 & 13017.192 & 49939.335 & 7341.404 \\
\hline & Bayesian inform. criterion (BIC) & 129846.791 & 83731.192 & 13209.882 & 50175.834 & 7516.023 \\
\hline \multirow{2}{*}{$\begin{array}{l}\text { Sample } \\
\text { size }\end{array}$} & Countries; country-waves; & $32 ; 166$ & $32 ; 166$ & $32 ; 166$ & $32 ; 166$ & $32 ; 166$ \\
\hline & Respondents & 39091 & 25659 & 3699 & 15199 & 2065 \\
\hline
\end{tabular}

${ }^{*} p<.05 .{ }^{* *} p<.01 .{ }^{* * *} p<.001$. 


\section{Table 6}

\section{Comparison of Fit Indicators between the Proposed Model and an Alternative Model}

\begin{tabular}{lccc}
\hline Fit indicators & Proposed model & Alternative model \\
\hline Unexplained variance at within level & $1.678(0.000)^{* * *}$ & $3.224(0.000)^{* * *}$ \\
Unexplained variance at between-level & $0.070(0.004)^{* *}$ & $0.124(0.000)^{* * *}$ \\
Fit indicators & Loglikelihood & -31439.821 & -37479.945 \\
& Akaike information criterion (AIC) & 62959.643 & 75042.890 \\
& Bayesian inform. criterion (BIC) & 63273.008 & 75363.037 \\
\hline
\end{tabular}

Note. The proposed model is the model of analysis 1 and the alternative model tests the same variables on well-being, controlling for health. 